\title{
Effects of permanent cardiac pacemaker implantation on vascular endothelial function, blood coagulation and cardiac function in patients with bradycardia
}

\author{
XINLING ZHANG $^{1 *}$, YAN LI $^{1 *}$, NAN WANG $^{2}$, CHUNXIANG ZHANG $^{1}$, DEBING ZHANG $^{1}$ and QIANG LI ${ }^{1}$ \\ ${ }^{1}$ The Heart Center, Jining First People's Hospital; ${ }^{2}$ Department of Stomatology, \\ Affiliated Hospital of Jining Medical University, Jining, Shandong 272011, P.R. China
}

Received April 9, 2018; Accepted September 24, 2018

DOI: $10.3892 /$ etm.2018.6808

\begin{abstract}
Changes in vascular endothelial function, blood coagulation and cardiac function indexes after the implantation of a permanent cardiac pacemaker in patients with bradycardia were investigated. A total of 53 healthy people and 117 patients with bradycardia in Jining First People's Hospital from January 2015 to August 2017 were selected. Factor VIII: coagulation (FVIII:C), von Willebr and factor (vWF), antithrombin activity (AT:A), D-dimmer (D-D), thrombomodulin (TM), tissue factor (TF), left ventricular ejection fraction (LVEF) and left ventricular end-systolic volume (LVESV) in the non-pacemaker group and the pacemaker group were significantly different from those in the control group $(\mathrm{P}<0.05)$, in which FVIII:C, vWF, D-D, TM, TF and LVESV were significantly higher than those in the control group, while LVEFs were significantly lower than that in the control group. After the implantation of a pacemaker, the FVIII:C, vWF, fibrinogen (FIB), D-D, TF and LVESV in patients were significantly higher than those before implantation $(\mathrm{P}<0.05)$, while the LVEF was significantly lower than that before implantation $(\mathrm{P}<0.05)$. In addition, in different pacemaker groups, there were no significant differences in blood coagulation and vascular endothelial indexes, but differences in cardiac function levels were obvious, in which LVEF in dual-chamber (DDD) pacemaker group was significantly higher than that in ventricular inhibited (VVI) pacemaker group, and LVESV in the former was significantly lower than that in the latter $(\mathrm{P}<0.05)$. Finally, here was no significant difference in the quality of life of patients implanted with different pacemakers $(\mathrm{P}>0.05)$, but the quality of life of
\end{abstract}

Correspondence to: Dr Qiang Li, The Heart Center, Jining First People's Hospital, Jining, Shandong 272011, P.R. China

E-mail: lnkvz386@163.com

${ }^{*}$ Contributed equally

Key words: bradycardia, pacemaker, vascular endothelial function, blood coagulation, heart function patients in the DDD pacemaker group was better than that of patients in the VVI group. Therefore, implanting pacemakers in patients with bradycardia affects vascular endothelial function, blood coagulation, and cardiac function indexes in patients, and complications become less after the implantation of DDD pacemakers.

\section{Introduction}

Cardiac pacemakers are generally used in the treatment of patients with bradycardia, through which patients' hemodynamic level can be improved, and their cardiac function can be regulated (1-3). However, clinical studies have shown that implanting a pacemaker may trigger complications related to blood coagulation, but relevant reports have not studied this in-depth (4-6). A total of 53 healthy people, 59 patients implanted with cardiac pacemakers and 58 patients implanted with no pacemaker in Jining First People's Hospital (Jining, China) from January 2015 to August 2017 were selected in this study, so as to explore the effects of permanent cardiac pacemaker implantation on vascular endothelial function, blood coagulation and cardiac function in patients with bradycardia.

\section{Patients and methods}

Study objects. A total of 53 healthy individuals and 117 patients with bradycardia in the hospital from January 2015 to August 2017 were selected. Among healthy people, there were 24 males and 29 females, with an average age of $(53.21 \pm 4.98)$ years. Among patients with bradycardia, there were 51 males and 66 females, including 44 cases of III-degree atrioventricular block, 33 cases of sick sinus syndrome, 12 cases of aortic stenosis, 22 cases of cardiomyopathy, and 6 cases of sinus bradycardia.

All patients were informed of clinical programs and signed an informed consent. This study was approved by the Ethics Committee of Jining First People's Hospital.

Inclusion criteria: Patients clinically and definitely diagnosed with bradycardia, patients with no significant differences in general data, and patients with good treatment compliance. 
Table I. Comparison of general clinical data of all patients.

\begin{tabular}{lccc}
\hline Items & Control group & Pacemaker group & Non-pacemaker group \\
\hline Average age (mean \pm SD, year) & $53.21 \pm 4.98$ & $55.29 \pm 5.03^{\mathrm{a}}$ & $51.21 \pm 5.11^{\mathrm{a}, \mathrm{b}}$ \\
No. of cases (n) & 53 & $59^{\mathrm{a}}$ & $58^{\mathrm{a}, \mathrm{b}}$ \\
Male (n) & 24 & $25^{\mathrm{a}}$ & $26^{\mathrm{a}, \mathrm{b}}$ \\
Basic diseases & & & $58^{\mathrm{a}}$ \\
Coronary heart disease (n) & 53 & $53^{\mathrm{a}}$ & $58^{\mathrm{a}, \mathrm{b}}$ \\
Hypertension (n) & 50 & $29^{\mathrm{a}}$ & $34^{\mathrm{a}, \mathrm{b}}$ \\
Diabetes (n) & 31 & $16^{\mathrm{a}}$ & $15^{\mathrm{a}, \mathrm{b}}$ \\
Chronic bronchitis (n) & 13 & \\
\hline
\end{tabular}

${ }^{\mathrm{a} C}$ Compared with the control group, $\mathrm{P}>0.05 ;{ }^{\mathrm{b}}$ compared with the pacemaker implantation group, $\mathrm{P}>0.05$.

Exclusion criteria: Patients with mental illness, and patients with severe damage in heart and liver or other vital organs.

Blood sample collection. Before the implantation of a pacemaker and at 7 days after the implantation, blood samples were collected, mixed and centrifuged at $2,500 \mathrm{xg}$ at $4{ }^{\circ} \mathrm{C}$ for $10 \mathrm{~min}$. Then the supernatant plasma was placed in a test tube, and stored in a refrigerator until detection. Blood samples were also collected from the healthy control group and the non-pacemaker implantation group, respectively, and the treatment methods for blood samples were the same as above.

Observation indexes and therapeutic effect evaluation. Prothrombin time (PT) and partial prothrombin time (PTT), factor VIII: coagulation (FVIII:C) activity, von Willebrand factor (vWF), fibrinogen (FIB) and D-dimer (D-D) were measured using the coagulation method $(7,8)$.

Thrombomodulin (TM) and tissue factor (TF) were detected using enzyme-linked immunosorbent assay (9).

Plasma antithrombin activity (AT:A) and plasminogen activity (PLG:A) were measured using chromogenic substrate method (10).

Left ventricular end-systolic volume (LVESV), left ventricular end-diastolic volume (LVEDV) and left ventricular ejection fraction (LVEF) were measured by echocardiography.

Criteria for quality of life assessment: The Cancer Quality of Life Questionnaire Core 30 (QLQ-C30) scale is divided into four items including physical, psychological, social and material functions, and the higher the score is, the higher the quality of life is (11).

Complications: Lung infections, constipation, local incision infection, damage to the integrity of the skin.

Statistical analysis. Data were processed and analyzed using Statistical Product and Service Solutions (SPSS) 17.0 software (SPSS, Chicago, IL, USA). Measurement data were expressed as (mean $\pm \mathrm{SD}$ ). Comparison between multiple groups was done using one-way ANOVA test followed by post hoc test (Least Significant Difference). Enumeration data were expressed as a number, and intergroup differences were detected using Chi-square test. $\mathrm{P}<0.05$ indicates that the difference is statistically different.

\section{Results}

Comparison of general clinical data of all patients. There were no significant differences in general data such as age, number of cases, sex distribution and basic diseases in the three groups of patients $(\mathrm{P}>0.05)$ (Table I).

Comparison of blood coagulation, vascular endothelial function and cardiac function indexes of patients among the control, non-pacemaker and pacemaker groups. FVIII:C, vWF, AT:A, D-D, TM, TF, LVEF and LVESV in the non-pacemaker and pacemaker groups were significantly different from those in the control group $(\mathrm{P}<0.05)$, in which FVIII:C, vWF, D-D, TM, TF, AT:A and LVESV were significantly higher than those in the control group, while LVEF was significantly lower than that in the control group. There were no significant differences in blood coagulation, vascular endothelial function and cardiac function indexes between the non-pacemaker and pacemaker groups $(\mathrm{P}>0.05)$ (Table II).

Comparison of vascular endothelial function, blood coagulation and cardiac function before and after the implantation of a pacemaker. FVIII:C, vWF, FIB, D-D, TF and LVESV in patients after the implantation of a pacemaker were significantly higher than those before the implantation $(\mathrm{P}<0.05)$, but LVEF was significantly lower than that before the implantation $(\mathrm{P}<0.05)$, and the differences were statistically significant (Table III).

Comparison of vascular endothelial function, blood coagulation and cardiac function after the implantation of different pacemakers. In different pacemaker groups, there were no significant differences in blood coagulation and vascular endothelial indexes, but differences in cardiac function levels were obvious, in which LVEF in dual-chamber (DDD) pacemaker group was significantly higher than that in ventricular inhibited (VVI) pacemaker group, and LVESV in the former group was significantly lower than that in the latter group $(\mathrm{P}<0.05)$ (Table IV).

Comparison of the quality of life after the implantation of different pacemakers. There was no significant difference in the 
Table II. Comparison of blood coagulation, vascular endothelial function and cardiac function indexes of patients among the control group, the non-pacemaker group and the pacemaker group.

\begin{tabular}{lccc}
\hline Items & $\begin{array}{c}\text { Control } \\
\text { group }\end{array}$ & $\begin{array}{c}\text { Non-pacemaker } \\
\text { group }\end{array}$ & $\begin{array}{c}\text { Pacemaker } \\
\text { group }\end{array}$ \\
\hline PT (s) & $12.6 \pm 1.21$ & $13.2 \pm 1.23^{\mathrm{a}}$ & $13.5 \pm 1.09^{\mathrm{a}}$ \\
PTT (s) & $36.5 \pm 4.65$ & $37.0 \pm 3.65$ & $36.6 \pm 3.42$ \\
FVIII:C (\%) & $120 \pm 9.97$ & $167 \pm 15.32^{\mathrm{a}}$ & $189 \pm 18.54^{\mathrm{a}}$ \\
VWF (\%) & $115 \pm 10.98$ & $144 \pm 11.23^{\mathrm{a}}$ & $161 \pm 12.98^{\mathrm{a}}$ \\
FIB (g/l) & $3.13 \pm 0.29$ & $3.20 \pm 0.13$ & $3.31 \pm 0.21$ \\
ATA $(\%)$ & $109 \pm 9.76$ & $199 \pm 7.89^{\mathrm{a}}$ & $193 \pm 9.07^{\mathrm{a}}$ \\
PLG:A (\%) & $98 \pm 8.65$ & $97 \pm 5.98$ & $96 \pm 8.98$ \\
D-D (mg/l) & $0.45 \pm 0.02$ & $0.86 \pm 0.06^{\mathrm{a}}$ & $0.86 \pm 0.08^{\mathrm{a}}$ \\
TM $(\mu \mathrm{g} / \mathrm{l})$ & $25.21 \pm 2.32$ & $43.21 \pm 3.89^{\mathrm{a}}$ & $48.21 \pm 4.01^{\mathrm{a}}$ \\
TF $(\mathrm{ng} / \mathrm{l})$ & $121.9 \pm 10.32$ & $259.7 \pm 20.32^{\mathrm{a}}$ & $267.4 \pm 20.54^{\mathrm{a}}$ \\
LVEF $(\%)$ & $67.25 \pm 5.98$ & $61.23 \pm 5.98^{\mathrm{a}}$ & $60.59 \pm 6.05^{\mathrm{a}}$ \\
LVESV (ml) & $34.61 \pm 3.21$ & $38.56 \pm 3.67^{\mathrm{a}}$ & $39.21 \pm 3.87^{\mathrm{a}}$ \\
LVEDV (ml) & $101.89 \pm 9.99$ & $101.21 \pm 9.98$ & $102.32 \pm 10.01$ \\
\hline
\end{tabular}

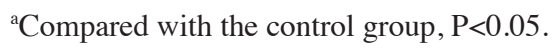

Table III. Comparison of vascular endothelial function, blood coagulation and cardiac function before and after the implantation of a pacemaker.

\begin{tabular}{lcc}
\hline Items & Before the implantation & After the implantation \\
\hline PT (s) & $13.4 \pm 1.21$ & $13.0 \pm 1.23$ \\
PTT (s) & $36.9 \pm 2.98$ & $35.21 \pm 2.78$ \\
FVIII:C (\%) & $173 \pm 12.45$ & $192.3 \pm 8.89^{\mathrm{a}}$ \\
VWF (\%) & $152 \pm 11.09$ & $161.2 \pm 12.54^{\mathrm{a}}$ \\
FIB $(\mathrm{g} / \mathrm{l})$ & $3.21 \pm 0.29$ & $4.21 \pm 0.37^{\mathrm{a}}$ \\
ATA $(\%)$ & $197 \pm 8.76$ & $236 \pm 8.98^{\mathrm{a}}$ \\
PLG:A $(\%)$ & $97 \pm 8.98$ & $99 \pm 8.76$ \\
D-D (mg/l) & $0.86 \pm 0.05$ & $1.59 \pm 0.11^{\mathrm{a}}$ \\
TM $(\mu \mathrm{g} / \mathrm{l})$ & $47.2 \pm 3.98$ & $73.2 \pm 6.78^{\mathrm{a}}$ \\
TF $(\mathrm{ng} / \mathrm{l})$ & $269.3 \pm 23.65$ & $421.5 \pm 38.98^{\mathrm{a}}$ \\
LVEF $(\%)$ & $61.59 \pm 5.98$ & $53.23 \pm 4.98^{\mathrm{a}}$ \\
LVESV $(\mathrm{ml})$ & $38.79 \pm 2.98$ & $47.21 \pm 4.21^{\mathrm{a}}$ \\
LVEDV $(\mathrm{ml})$ & $101.59 \pm 9.76$ & $97.23 \pm 9.65$ \\
\hline
\end{tabular}

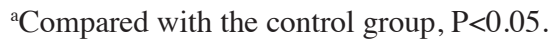

quality of life of patients implanted with different pacemakers ( $P>0.05)$, but the quality of life of patients in the DDD group was higher than that of patients in the VVI group (Table V).

Comparison of complications in patients implanted with different pacemakers. Complications were found after the implantation of pacemakers. It was found that the incidence
Table IV. Comparison of vascular endothelial function, blood coagulation and cardiac function after the implantation of different pacemakers.

\begin{tabular}{lcc}
\hline Items & DDD & VVI \\
\hline PT (s) & $13.0 \pm 1.21$ & $13.0 \pm 2.32$ \\
PTT (s) & $35.21 \pm 3.21$ & $35.21 \pm 2.87$ \\
FVIII:C (\%) & $192.3 \pm 17.32^{\mathrm{a}}$ & $192.3 \pm 12.21^{\mathrm{a}}$ \\
VWF (\%) & $161.2 \pm 15.21^{\mathrm{a}}$ & $161.2 \pm 11.09^{\mathrm{a}}$ \\
FIB $(\mathrm{g} / \mathrm{l})$ & $4.21 \pm 0.34^{\mathrm{a}}$ & $4.21 \pm 0.34^{\mathrm{a}}$ \\
ATA $(\%)$ & $196 \pm 8.65$ & $221 \pm 7.77^{\mathrm{a}}$ \\
PLG:A $(\%)$ & $99 \pm 8.98$ & $99 \pm 9.01$ \\
D-D $(\mathrm{mg} / \mathrm{l})$ & $1.59 \pm 0.10^{\mathrm{a}}$ & $1.59 \pm 0.12^{\mathrm{a}}$ \\
TM $(\mu \mathrm{g} / \mathrm{l})$ & $73.2 \pm 6.78^{\mathrm{a}}$ & $73.2 \pm 6.78^{\mathrm{a}}$ \\
TF $(\mathrm{ng} / \mathrm{l})$ & $421.5 \pm 34.65^{\mathrm{a}}$ & $421.5 \pm 38.43^{\mathrm{a}}$ \\
LVEF $(\%)$ & $59.21 \pm 5.67$ & $53.04 \pm 4.98^{\mathrm{b}}$ \\
LVESV $(\mathrm{ml})$ & $38.87 \pm 3.98$ & $48.93 \pm 6.76^{\mathrm{b}}$ \\
LVEDV $(\mathrm{ml})$ & $100.34 \pm 8.97$ & $100.98 \pm 8.99$ \\
\hline
\end{tabular}

${ }^{\mathrm{a}} \mathrm{P}>0.05 ;{ }^{\mathrm{b}}$ compared with the DDD group.

Table V. Comparison of the quality of life after the implantation of different pacemakers.

\begin{tabular}{lcc}
\hline Items & DDD & VVI \\
\hline Somatic function & $66.23 \pm 5.67$ & $64.23 \pm 5.67^{\mathrm{a}}$ \\
Body pain & $75.23 \pm 6.32$ & $70.56 \pm 5.76^{\mathrm{a}}$ \\
Somato-role & $63.29 \pm 3.45$ & $51.23 \pm 5.01^{\mathrm{a}}$ \\
Health score & $52.49 \pm 4.01$ & $46.23 \pm 3.98^{\mathrm{a}}$ \\
Life vitality & $59.26 \pm 4.56$ & $56.31 \pm 5.02^{\mathrm{a}}$ \\
Emotional character & $69.21 \pm 5.87$ & $61.23 \pm 5.67^{\mathrm{a}}$ \\
Mental health & $67.21 \pm 6.01$ & $70.56 \pm 6.32^{\mathrm{a}}$ \\
Social function & $51.63 \pm 5.01$ & $49.99 \pm 4.21^{\mathrm{a}}$ \\
\hline
\end{tabular}

${ }^{\mathrm{a}}$ Compared with the DDD group, $\mathrm{P}>0.05$.

rate of complications was $66.6 \%$ in the VVI group and $48.3 \%$ in the DDD group. The incidence rate in the DDD group was significantly lower than that in the VVI group $(\mathrm{P}<0.05)$, and the difference was statistically significant (Table VI).

\section{Discussion}

Cardiac pacemaker implantation is the main treatment method for bradycardia, and pacemakers are mainly divided into the DDD and VVI pacemakers $(12,13)$. The implantation of pacemakers improves symptoms of bradycardia, but a series of side effects such as increased thrombus formation occur, and there are few clinical studies on thrombosis and blood coagulation (14-16). Therefore, changes in blood coagulation and endothelial function after the implantation of pacemakers in patients with bradycardia were mainly explored in this study. 
Table VI. Comparison of complications in patients implanted with different pacemakers.

\begin{tabular}{lcccccc}
\hline Groups & $\mathrm{N}$ & $\begin{array}{c}\text { Pulmonary } \\
\text { infection }(\mathrm{n})\end{array}$ & $\begin{array}{c}\text { Constipation } \\
(\mathrm{n})\end{array}$ & $\begin{array}{c}\text { Local incision } \\
\text { infection }(\mathrm{n})\end{array}$ & $\begin{array}{c}\text { Damage of skin } \\
\text { integrity (n) }\end{array}$ & $\begin{array}{c}\text { Incidence of } \\
\text { complications (\%) }\end{array}$ \\
\hline VVI & 24 & 7 & 3 & 3 & 5 & $16(66.6)$ \\
DDD & 29 & 5 & 4 & 1 & 4 & $14(48.3)^{\mathrm{a}}$ \\
\hline
\end{tabular}

${ }^{\mathrm{a} C}$ Compared with the VVI group, $\mathrm{P}<0.05$.

A variety of indexes can be used to evaluate blood coagulation, endothelial function and cardiac function, in which PT, PTT and vWF and other factors are mainly used for blood coagulation and endothelial function (17). The blood coagulation function is mainly related to vascular endothelial cells, which can secrete various factors after blood vessels are damaged, thus exerting an antithrombotic effect. TM is a protein factor secreted by vascular endothelial cells. When vascular endothelial cells are impaired, the secretion of this factor is increased. At the same time, the synthesis of vWF is accelerated, and the content of TF in the plasma is increased. The above indicators are markers for endothelial cell damage. Plasma AT:A can be used to show how much thrombin is produced in the body. In addition, when the amount of vWF in the body is increased, then, the activity of FVIII:C is also increased, indicating that the body is in a blood coagulation-activated state. PLG:A is a single-chain glycoprotein that is homeostatic when umbilical vessels are undamaged, but when vascular endothelia are damaged, this glycoprotein is activated to be converted into plasmin, which degrades cross-linked fibrin in plasma, leading to increased content of D-D in plasma and further triggering hypercoagulable symptoms $(5,6,18)$.

It was found in this study that there were significant differences in FVIII:C, vWF,AT:A,D-D, TM, TF, LVEF and LVESV between the bradycardia group and the healthy control group $(\mathrm{P}<0.05)$, in which FVIII:C, vWF, D-D, TM, TF and LVESV in the bradycardia group were significantly higher than those in the control group, while LVEF was significantly lower than that in the control group, indicating that blood coagulation index, as well as endothelial and cardiac function in patients with bradycardia are damaged. FVIII:C, vWF, FIB, D-D, TF and LVESV in patients after the implantation of pacemakers were significantly higher than those before implantation $(\mathrm{P}<0.05)$, but LVEF was significantly lower than that before implantation $(\mathrm{P}<0.05)$. Besides, the changes in the above indexes became more obvious after the implantation of VVI pacemakers, and the change degree was significantly higher than that of DDD group $(\mathrm{P}<0.05)$, suggesting that the effect of VVI pacemakers on blood coagulation, as well as endothelial and cardiac function is more obvious. After the implantation of VVI pacemakers, the blood coagulation indexes, TM, vWF and TF changed greatly, indicating that after implantation, the vascular endothelial cells are damaged, thereby significantly increasing the plasma coagulation in vivo and increasing the incidence rate of hypercoagulability. After the implantation of VVI pacemakers, LVEF was more obviously reduced, indicating that VVI pacemakers significantly reduce the cardiac contractility of patients, reduce cardiac output, and affect cardiac function, and they may also activate the sympathetic nerve, which results in changes in myocardial cell structures, thus secreting too many atrial natriuretic peptides and increasing the incidence rate of atrial fibrillation. In terms of the quality of life, it was found that after implantation, the score of the VVI pacemaker was significantly lower than that of the DDD pacemaker, indicating that the VVI pacemaker brings great inconvenience to the life and work of patients. In addition, the incidence of complications in the DDD group was only $48.3 \%$, which was significantly lower than that in the VVI group $(66.6 \%, \mathrm{P}<0.05)$, indicating that the use of DDD pacemakers can reduce adverse reactions with good therapeutic effects.

In conclusion, the use of DDD pacemakers in bradycardia patients can improve the therapeutic effects, reduce complications, improve patients' quality of life, and reduce the effects on blood coagulation, as well as endothelial and cardiac function in patients, which has high clinical treatment value.

\section{Acknowledgements}

Not applicable.

\section{Funding}

No funding was received.

\section{Availability of data and materials}

All data generated or analyzed during this study are included in this published article.

\section{Authors' contributions}

$\mathrm{XZ}$ and QL designed the study and performed the experiments. YL, NW and CZ collected the data. YL and DZ analyzed the data. XZ and YL prepared the manuscript. All authors have read and approved the final manuscript.

\section{Ethics approval and consent to participate}

This study was approved by the Ethics Committee of Jining First People's Hospital (Jining, China). Signed informed consents were obtained from the patients or guardians.

\section{Patient consent for publication}

Not applicable. 


\section{Competing interests}

The authors declare no competing interests.

\section{References}

1. Tracy CM, Epstein AE, Darbar D, DiMarco JP, Dunbar SB Estes NR, Ferguson TJ, Hammill SC, Karasik PE, Link MS, et al: 2012 ACCF/AHA/HRS focused update of the 2008 guidelines for device-based therapy of cardiac rhythm abnormalities: A report of the American College of Cardiology Foundation/American Heart Association Task Force on Practice Guidelines and the Heart Rhythm Society. Circulation 126: 1784-1800, 2012.

2. Edwards SJ, Karner C, Trevor N, Wakefield V and Salih F: Dual-chamber pacemakers for treating symptomatic bradycardia due to sick sinus syndrome without atrioventricular block: A systematic review and economic evaluation. Health Technol Assess 19: 1-210, 2015

3. Gupta PK and Boro AK: Need for pacemaker in drug induced bradycardia. Indian Heart J 69: S70, 2017.

4. Tian J, An XJ and Fu MY: Transient receptor potential melastatin 4 cation channel in pediatric heart block. Eur Rev Med Pharmacol Sci 21: 79-84, 2017.

5. Ellims AH, Mariani JA and Schlaich MP: Restoration of blood pressure control with pacemaker implantation in a patient with bradycardia and resistant hypertension: A case report. Int J Cardiol 167: e38-e40, 2013

6. Nikolaou NI, Christou AH, Spanodimos SG, Antonatos DG Korkonikitas PI and Patsilinakos SP: Marked troponin elevation after implantation of a permanent antibradycardia pacemaker. Hellenic J Cardiol 52: 489-492, 2011.

7. Olson NC, Raffield LM, Lange LA, Lange EM, Longstreth WJ Jr, Chauhan G, Debette S, Seshadri S, Reiner AP and Tracy RP. Associations of activated coagulation factor VII and factor VIIaantithrombin levels with genome-wide polymorphisms and cardiovascular disease risk. J Thromb Haemost 16: 19-30, 2018.

8. DiBiase A, Tse TM, Schnittger I, Wexler L, Stinson EB and Valantine HA: Frequency and mechanism of bradycardia in cardiac transplant recipients and need for pacemakers. Am J Cardiol 67: 1385-1389, 1991

9. Camm AJ, Kirchhof P, Lip GY, Schotten U, Savelieva I, Ernst S, Van Gelder IC, Al-Attar N, Hindricks G, Prendergast B, et al: Guidelines for the management of atrial fibrillation: The Task Force for the Management of Atrial Fibrillation of the European Society of Cardiology (ESC). Eur Heart J 31: 2369-2429, 2010.
10. Kuijpers MJ, Schulte V, Oury C, Lindhout T, Broers J, Hoylaerts MF, Nieswandt B and Heemskerk JW: Facilitating roles of murine platelet glycoprotein $\mathrm{Ib}$ and alphaIIbbeta3 in phosphatidylserine exposure during vWF-collagen-induced thrombus formation. J Physiol 558: 403-415, 2004

11. Theodoropoulos GE, Memos NA, Peitsidou K, Karantanos T, Spyropoulos BG and Zografos G: Synbiotics and gastrointestinal function-related quality of life after elective colorectal cancer resection. Ann Gastroenterol 29: 56-62, 2016.

12. Lichtenberger J, Scollan KF, Bulmer BJ and Sisson DD Long-term outcome of physiologic VDD pacing versus nonphysiologic VVI pacing in dogs with high-grade atrioventricular block. J Vet Cardiol 17: 42-53, 2015

13. Madershahian N, Scherner M, Weber C, Kuhn E, Choi YH, Slottosch I and Wahlers T: Temporary biventricular pacing improves bypass graft flows in coronary artery bypass graft patients with permanent atrial fibrillation. Interact Cardiovasc Thorac Surg 21: 435-440, 2015.

14. Udo EO, van Hemel NM, Zuithoff NP, Nijboer H, Taks W, Doevendans PA and Moons KG: Long term quality-of-life in patients with bradycardia pacemaker implantation. Int $\mathbf{J}$ Cardiol 168: 2159-2163, 2013.

15. Choi SH, Choi SL, Lee BY and Jeong MA: Tachycardiabradycardia syndrome in a patient with atrial fibrillation: A case report. Korean J Anesthesiol 68: 415-419, 2015.

16. Udo EO, van Hemel NM, Zuithoff NP, Doevendans PA and Moons KG: Prognosis of the bradycardia pacemaker recipient assessed at first implantation: A nationwide cohort study. Heart 99: 1573-1578, 2013.

17. Iorio A, Federici MO, Mourvaki E, Ferolla P, Piroddi M, Stabile A, Timi A, Celleno R and Benedetti MM: Impaired endothelial antithrombotic activity following short-term interruption of continuous subcutaneous insulin infusion in type 1 diabetic patients. Thromb Haemost 98: 635-641, 2007.

18. Lo LW, Tuan TC, Tai CT, Lin YJ, Chang SL and Chen SA: Incessant wide QRS tachycardia after pulmonary vein isolation and pacemaker implantation in a patient with tachycardia-bradycardia syndrome. J Cardiovasc Electrophysiol 18: 783-784, 2007.

(i) $(-)$ This work is licensed under a Creative Commons Attribution-NonCommercial-NoDerivatives 4.0 International (CC BY-NC-ND 4.0) License. 